\title{
Multiband Fractal PIFA (Planar Inverted F Antenna) for Mobile Phones
}

\author{
N.A. Saidatu ${ }^{\# 1}$, P.J. Soh ${ }^{\# 2}$, Y. Sun ${ }^{* 3}$, D. Lauder ${ }^{* 4}$, A.A.H. Azremi ${ }^{\# 5}$ \\ \# School of Computer and Communication Engineering, University Malaysia Perlis (UniMAP) \\ Block A Seberang Ramai, \\ 02000 Kuala Perlis, Perlis Malaysia. \\ ${ }^{1}$ snorlyana@unimap.edu.my \\ ${ }^{2}$ pj soh@unimap.edu.my \\ ${ }^{5}$ azremi@unimap. edu.my \\ * School of Engineering and Technology, University of Hertfordshire \\ Hatfield, Herts AL10 9AB \\ United Kingdom. \\ ${ }^{3} \mathrm{y}$. sun@herts.ac.uk \\ ${ }^{4}$ d.m.lauder@herts.ac.uk
}

\begin{abstract}
A novel Fractal planar inverted F antenna F-PIFA) based on the self affinity design is presented in this paper. The procedure for designing a Fractal Planar Inverted F Antenna is explained and the $\mathbf{2}^{\text {nd }}$ iteration of Sierpinski Carpet is chosen as an antenna for mobile phones. The F-PIFA has a total dimension of $27 \mathrm{~mm} \times 27 \mathrm{~mm}$ and is designed and optimized to receive GSM (Global System for Mobile Communication) and UMTS (Universal Mobile Telecommunication System) and HiperLAN (High Performance Radio LAN). The frequency ranges are from $1900 \mathrm{MHz}$ to $2100 \mathrm{MHz}, 1885$ to $2200 \mathrm{MHz}$ for $3 G$ and $4800 \mathrm{MHz}$ to $5800 \mathrm{MHz}$ for HiperLAN respectively. The antenna covered the GSM, UMTS and HiperLan frequency ranges with $-6 \mathrm{~dB}$ return loss and has an almost omni-directional radiation pattern. This antenna has been tested using a mobile phone model and the performance met all the criteria for a mobile phone application.
\end{abstract}

\section{INTRODUCTION}

In the past, the common mobile phone antennas were the whip and monopole. Conventional monopole and whip antennas are simple, inexpensive with omni-directional pattern and gain that are suitable for mobile application. The design remained relatively large compared to the handset itself, and lacked shielding mechanisms. However, demand for small size mobile phone devices is increasing, and the requirement that the same mobile phone can operate at different frequency bands is also important. Currently at least five bands are assigned for world-wide mobile services $(850$, $900,1800,1900$ and $2100 \mathrm{MHz}$ ) and high efficiency is required. These days, many mobile phones also have Bluetooth and Wireless LAN capability. By adding Bluetooth or WLAN at the mobile phone, data transfer can easily be made. Bluetooth or WLAN Communication Systems use frequency range from $2400-2483 \mathrm{MHz}$, hence the antenna designed must be able to operate in that frequency range.

The Planar inverted-F antenna (PIFA) is currently being used as an embedded antenna in many radiotelephone handsets [1-4]. It is one of the most promising antenna types since it is small and has a low profile, making it suitable for mounting on portable equipment. The planar inverted-F antenna is a microstrip antenna design that shows much promise in dealing with the shortcomings of the $\lambda / 4$ monopole antenna in mobile communication applications [5-6]. The antenna also has a high degree of sensitivity to both vertically and horizontally polarized radio waves, thus making the Planar Inverted-F Antenna ideally suited to mobile applications. In addition, PIFAs can reduce the possible electromagnetic energy absorption by the mobile handset user's head, because of relatively smaller backward radiation toward the user. [7]

However, PIFA antennas have some disadvantages such as low efficiency, narrow bandwidth and no multiband capability. To overcome these drawbacks, especially narrow bandwidth, and to meet the miniaturization requirements of mobile units, the Fractal PIFA antenna has been proposed to achieve the design of internal compact and broadband microstrip patch antennas. Fractal antennas consist of elements patterned after self-similar designs to maximize the length, or increase the perimeter [8]. These have useful applications in cellular telephone and microwave communications. Furthermore, it is found that a small adjustment of the shape can make it work at the required resonant frequencies [9-11]. At the present time, there is no research into the combination of fractal to PIFA topology. Therefore, this paper proposes PIFA fractals, which can be used as an internal antenna solution with a wideband frequency response. In order to obtain a good fundamental antenna design, the initial studies were carried out theoretically, using CST Microwave Studio simulation software.

\section{ANTENNA DESIGN}

As mobile phones are becoming smaller with time, it is not feasible for separate antenna elements to be used to facilitate multiband operations. This paper proposes a novel design using a Sierpinski Carpet Fractal antenna as the patch for PIFA that is directly connected with a feed strip and is 


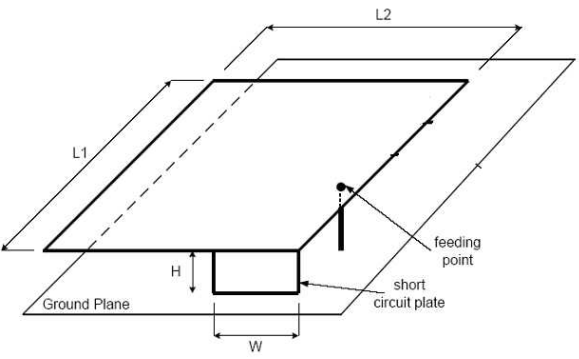

Fig. 1: Geometry of the proposed PIFA

positioned in a plane perpendicular to a ground plane. The antenna is designed using CST Studio Suit 2008 software.

The configuration of the proposed PIFA is shown in Fig. 1. The rectangular radiating patch is printed on Rogers board (Rogers, RO4003C) with epsilon 3.38, and dimensions $L 1 \mathrm{x} L 2$. It is located in the centre of a $0.5 \mathrm{~mm}$ thick copper plate ground plane with dimensions $L g x W g$. The antenna height $h$, $8 \mathrm{~mm}$ is filled with an air substrate $\left(\varepsilon_{\mathrm{r}}=1.0\right)$. The shorting plate consists of a vertical conducting strip and it is used not only to connect between the patch and ground, but also to support the whole antenna. The $50 \Omega$ coaxial probe has a radius of $0.5 \mathrm{~mm}$ and is fed on the centre line of the rectangular patch. The distance between the feeding position and the shorting plate varies depending on the fractal's iterations. The coaxial feed excites the PIFA's TM10 mode.

The operating frequency of a microstrip patch antenna is inversely proportional to its physical dimensions. For a standard, coax-fed, quarter-wave microstrip patch antenna, the operating frequency can be approximately determined from the length of antenna patch as follows:

$$
f=\frac{c}{4\left(\lambda_{d}\right)}
$$

where $\lambda_{d}$ is the wavelength inside the substrate $(L 1+L 2)$. The length $L 1$ and the width $L 2$ is subsequently optimized to obtain an improved frequency match by doing an optimization procedure through experimental trials. One method of reducing PIFA size is simply by shortening the antenna by adding a shorting pin. This approach affects the impedance at the antenna terminals such that the radiation resistance becomes reactive but this can be compensated with capacitive top loading. In practice, the missing antenna height is replaced with an equivalent circuit, which improves the impedance match and the efficiency. The ideal fractal antenna is obtained by iterating an infinite number of times. Fig. 2 shows the process of iteration for a Fractal design. The Fractal design is printed on a thin Rogers 4003 substrate of dielectric constant $\varepsilon_{r}=0.813$ with thickness $=0.813 \mathrm{~mm}$.

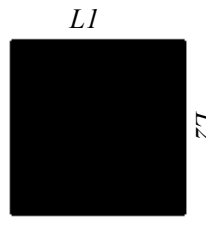

(a)

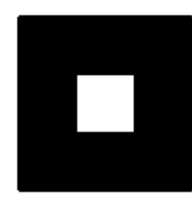

(b)

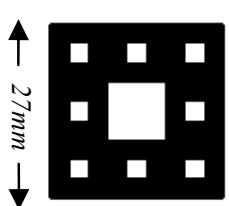

(c)

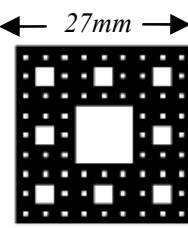

(d)
Fig. 2: Dimension for Fractal PIFA (a) 0 Iteration (b) $1^{\text {st }}$ Iteration (c) $2^{\text {nd }}$ Iteration (d) $3^{\text {rd }}$ Iteration

\section{ANTENNA RESULT AND DISCUSSION}

For the antenna results shown in Fig. 3, the measured bandwidths for $-9.8 \mathrm{~dB}$ return loss $(2: 1 \mathrm{VSWR})$ are as follows. For iteration 0 the bandwidth is $850 \mathrm{MHz}(1700-2550 \mathrm{MHz})$, while for the $1^{\text {st }}$ iteration it is $940 \mathrm{MHz}(1770-2710 \mathrm{MHz})$. The $2^{\text {nd }}$ iteration gives a bandwidth of $590 \mathrm{MHz}(1630-2220 \mathrm{MHz})$ in the lower band and $1520 \mathrm{MHz}(4780-5300 \mathrm{MHz})$ in the upper band. For the $3^{\text {rd }}$ iteration, the bandwidth is $500 \mathrm{MHz}$ $(1700-2200 \mathrm{MHz})$ in the lower band and $400 \mathrm{MHz}(4830-$ $5230 \mathrm{MHz}$ ) in the upper band. These results are shown in Table I. It can be clearly seen that the $1^{\text {st }}$ iteration produced a wider bandwidth compared to the other iterations, so the antenna has the capacity to cover GSM 1800, GSM 1900, UMTS 2000. As the number of iterations increases, the bandwidth becomes narrower but excite another resonant frequency at $5 \mathrm{GHz} .2^{\text {nd }}$ iteration achieves the bandwidth for $3 \mathrm{G}$ UMTS and HiperLAN. Thus, the F-PIFA design stops increasing the number of iterations and starts to study the behavior of F-PIFA at the $2^{\text {nd }}$ iteration.

\section{IV.F-PIFA AS INTERNAL ANTENNA}

As the antenna design is completed, the next step is to evaluate the performance of this antenna in a complete phone model. This enables the evaluation of the coupling effects of neighboring object such as the battery, camera, as well as the influence of dielectric materials such as the housing and display screen. The Fractal Planar Inverted F Antenna was integrated and positioned in the space provided on a mobile phone circuit board as shown in Fig. 4. A $2 \mathrm{~mm} \times 60 \mathrm{~mm}$ strip of copper plate was added in front of the F-PIFA in order to excite the $900 \mathrm{MHz}$ resonance. The new Fractal Planar Inverted F Antenna covers the GSM800, 900, 1800 and 1900 $\mathrm{MHz}$ bands, together with Wireless LAN $2400 \mathrm{MHz}$ for the $802.11 \mathrm{~b}$ and $-\mathrm{g}$ standards and $5000 \mathrm{MHz}$ for $802.11 \mathrm{a}$ standard.

Fig. 5 indicates the $S_{11}$ result for the F-PIFA with and without the full phone model. The bandwidth of the antenna is calculated at $-6 \mathrm{~dB}$ return loss by taking its limits at the upper frequency and lower frequency. Due to the fact that integrated antennas with a ground plane are known to radiate about $30 \%$ less power into the user's head, the bandwidth for a mobile phone is often calculated at $-6 \mathrm{~dB}$ [12]. It can be seen that when the antenna is covered with the mobile phone, the resonance is shifted to the left. The plastic housing will lower the resonant frequency due to dielectric loading, so the antenna has to be tuned to achieve the correct resonance. Thus the antenna length needs to be reduced slightly to move the resonance up until it resonates in the correct band. The changing resonant frequency can be observed using a network analyzer. This is the way to optimize the antenna.

Tabulated in Tables II and III are the results of efficiency and gain. Based on the results shown, this antenna is suitable for use as an internal antenna for mobile communication. As can be seen, the antenna radiation efficiency with the full phone model is still more than 50\%. Even though the measured results with and without the full phone are slightly different, these results are still acceptable due to the minimal degree of difference, which is less than $10 \%$. The degradation 
is due to the reflection caused by the mismatch between antenna and its feed line and absorption by circuit and other component inside the handset.

RF energy is coupled into the drive circuit for loudspeaker, cameras and other component contribute losses by coupling energy although it is not close to the antenna. Fig. 6 shows the antenna position during the measurement taken inside an anechoic chamber; while Fig. 7 shows the $3 \mathrm{D}$ radiation patterns of the phone with and without a phantom head. Based on the results shown in Fig. 7, the radiation pattern is obviously influenced by the phantom head. The F-PIFA radiation pattern at the first, second and third frequency is almost omni-directional while the E-plane is linear. However, when the planar antenna operates at the fourth frequency which is $5000 \mathrm{MHz}$, the polarization becomes directional. Therefore the gain at this resonance is higher $(3.57 \mathrm{~dB})$ compared to the first and the second resonance as the antenna becomes more directional. Without a phantom head, an omnidirectional radiation pattern is produced. However, the overall pattern shows an almost omni-directional radiation pattern, thus it is well suited for mobile phone applications.

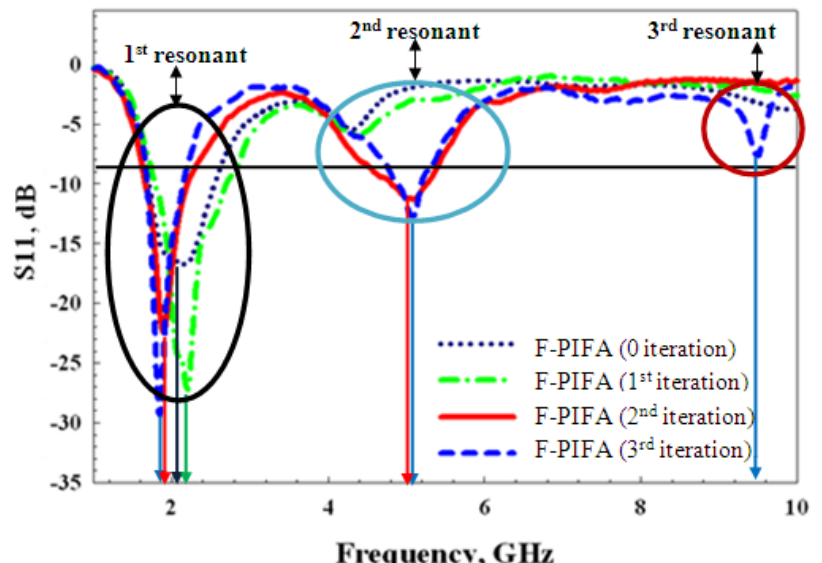

Fig. 3: The measured $S_{11}$ result for the designed antenna

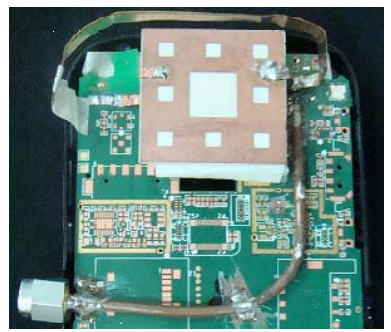

Fig. 4: F-PIFA mounted on the candy bar phone.

TABLE I

BANDWIDTH FOR MEASURED OF F - PIFA.

\begin{tabular}{|c|c|c|}
\hline F - PIFA & Frequency Band (MHz) & Bandwidth (BW) $(\mathrm{MHz})$ \\
\hline 0 Iteration & $1700-2550$ & $850(42.5 \%)$ \\
\hline $1^{\text {st }}$ Iteration & $1770-2710$ & $940(47 \%)$ \\
\hline $2^{\text {nd }}$ Iteration & $1630-2220$ & $590(29.5 \%)$ \\
\cline { 2 - 3 } & $4780-5300$ & $520(10.4 \%)$ \\
\hline \multirow{2}{*}{$3^{\text {rd }}$ Iteration } & $1700-2200$ & $500(25 \%)$ \\
\cline { 2 - 3 } & $4830-5230$ & $400(8 \%)$ \\
\hline
\end{tabular}

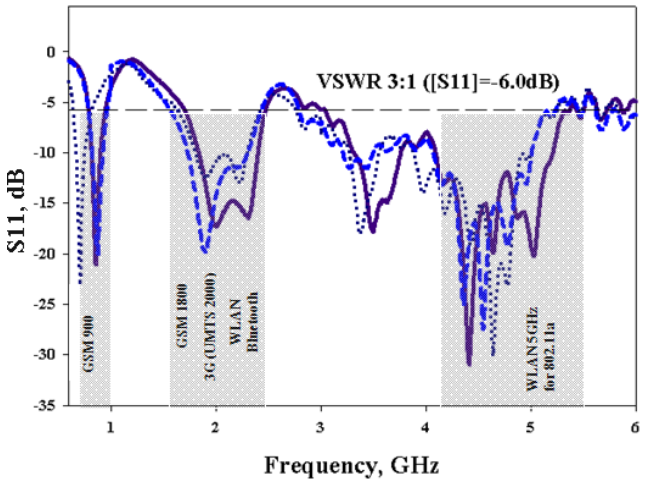

- Fractal PIFA inside phone model (after optimized)
…... Fractal PIFA inside phone model (before optimized)
- - Fractal PIFA without phone model

Fig. 5: F-PIFA $\mathrm{S}_{11}$ result

TABLE II

TOTAL EFFICIENTCY RESULTS OF F-PIFA

\begin{tabular}{|c|c|c|}
\hline Frequency (MHz) & $\begin{array}{c}\text { Total Efficiency } \\
\text { Measured (\%) }\end{array}$ & $\begin{array}{c}\text { Total Efficiency } \\
\text { Simulated (\%) }\end{array}$ \\
\hline GSM 900 (824-960) & $80-84$ & $78-80$ \\
\hline $\begin{array}{c}\text { GSM 1900 (1710- } \\
2170)\end{array}$ & 80 & $75-78$ \\
\hline 3G (1885-2200) & 80 & $75-78$ \\
\hline $\begin{array}{c}\text { WLAN and Bluetooth } \\
(2400-2450)\end{array}$ & 80 & $68-75$ \\
\hline HiperLAN (4800 - 5800) & $72-78$ & 68 \\
\hline
\end{tabular}

TABLE III

MEASURED AND SIMULATED GAIN RESUlts OF PIFA

\begin{tabular}{|c|c|c|}
\hline Frequency $(\mathrm{MHz})$ & Gain Measured $(\mathrm{dB})$ & Gain Simulated $(\mathrm{dB})$ \\
\hline GSM 900 $(824-960)$ & $1.5-1.8$ & 2 \\
\hline GSM 1900 $(1710-2170)$ & $2-2.6$ & $2.6-3$ \\
\hline 3G (1885-2200) & $2-2.6$ & $2.6-3$ \\
\hline $\begin{array}{c}\text { WLAN and Bluetooth } \\
(2400-2450)\end{array}$ & $2.8-3$ & 3 \\
\hline HiperLAN $(4800-5800)$ & $2.7-3.6$ & $3.2-3.67$ \\
\hline
\end{tabular}

TABLE IV

MATERIAL PARAMETERS OF THE SAM PHANTOM.

\begin{tabular}{|c|c|c|c|c|}
\hline $\begin{array}{c}\text { SAM } \\
\text { Material }\end{array}$ & $\begin{array}{c}\text { Frequency } \\
{[\mathrm{GHz}]}\end{array}$ & $\begin{array}{c}\text { Relative } \\
\text { Permittivity } \\
(\varepsilon r)\end{array}$ & $\begin{array}{c}\text { Conductivity } \\
{[\mathrm{S} / \mathrm{m}]}\end{array}$ & $\begin{array}{c}\text { Density } \\
{\left[\mathrm{kg} / \mathrm{m}^{3}\right]}\end{array}$ \\
\cline { 1 - 3 } $\begin{array}{c}\text { SAM } \\
\text { Liquid }\end{array}$ & \multirow{2}{*}{2.0} & 40.0 & 1.40 & 1000 \\
\cline { 1 - 1 } $\begin{array}{c}\text { SAM } \\
\text { Shell }\end{array}$ & & 3.5 & 0 & 1000 \\
\hline
\end{tabular}

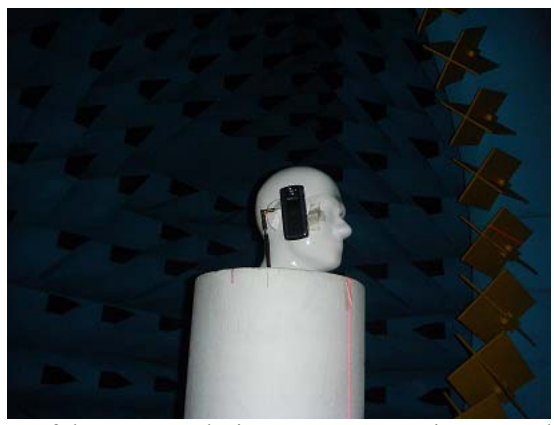

Fig. 6: Position of the antenna during measurement in an anechoic chamber. 
A final test for the mobile phone is to evaluate it in the presence of a human body with particular emphasis on the human head in terms of a unit referred to as specific absorption rate (SAR). The SAR value used in the assessment of mobile phones measures the amount of EM (ElectroMagnetic) energy absorbed by biological tissue. The SAR value is obtained by measuring the electric field in the simulated human tissues in close proximity to the device and is calculated ebove equation (2) [13]. Table IV shows the electrical properties of the brain.

$$
\mathrm{SAR}=\frac{\sigma}{\rho}|E|^{2}=\frac{J^{2}}{\rho \sigma}[W / k g]
$$

$E$ : rms value of the electric field strength in the tissue $[\mathrm{V} / \mathrm{m}]$;

$J$ : Current density $[\mathrm{A} / \mathrm{m}]$;

$\sigma$ : conductivity of body tissue $[\mathrm{S} / \mathrm{m}]$;

$\rho$ : density of body tissues $[\mathrm{kg} / \mathrm{m} 3]$
Fig. 8 shows the SAR calculation using a SAM Phantom Head. The position of the PIFA mounting headset is tilted by $30^{\circ}$ and is $0.5 \mathrm{~mm}$ away from the SAM Phantom Head. The SAR is calculated over 10 grams of the human tissue mass. The antenna is facing in the opposite direction from the human head. Fig. 7 shows that the PIFA radiation plots have a high Front to Back Ratio, which indicates a low SAR value of less than $2 \mathrm{~W} / \mathrm{kg}$. According to Swiss Regulations, the international SAR limit recommended for mobile phones is 2.0 watts per kilogram $(\mathrm{W} / \mathrm{kg})$ over 10 grams of tissue. For the United States Government, the SAR level is required to be at or below $1.6 \mathrm{~W} / \mathrm{kg}$ taken over a volume of 1 gram of tissue. However, SAR depends on the frequency of operation, antenna type and distance between the antenna and the human body. It increases as the frequency of operation increases and this is due to the penetration depth and the fact that at higher frequencies, more power is absorbed on the surface. Table V indicates the value of the maximum SAR that is simulated using CST software.

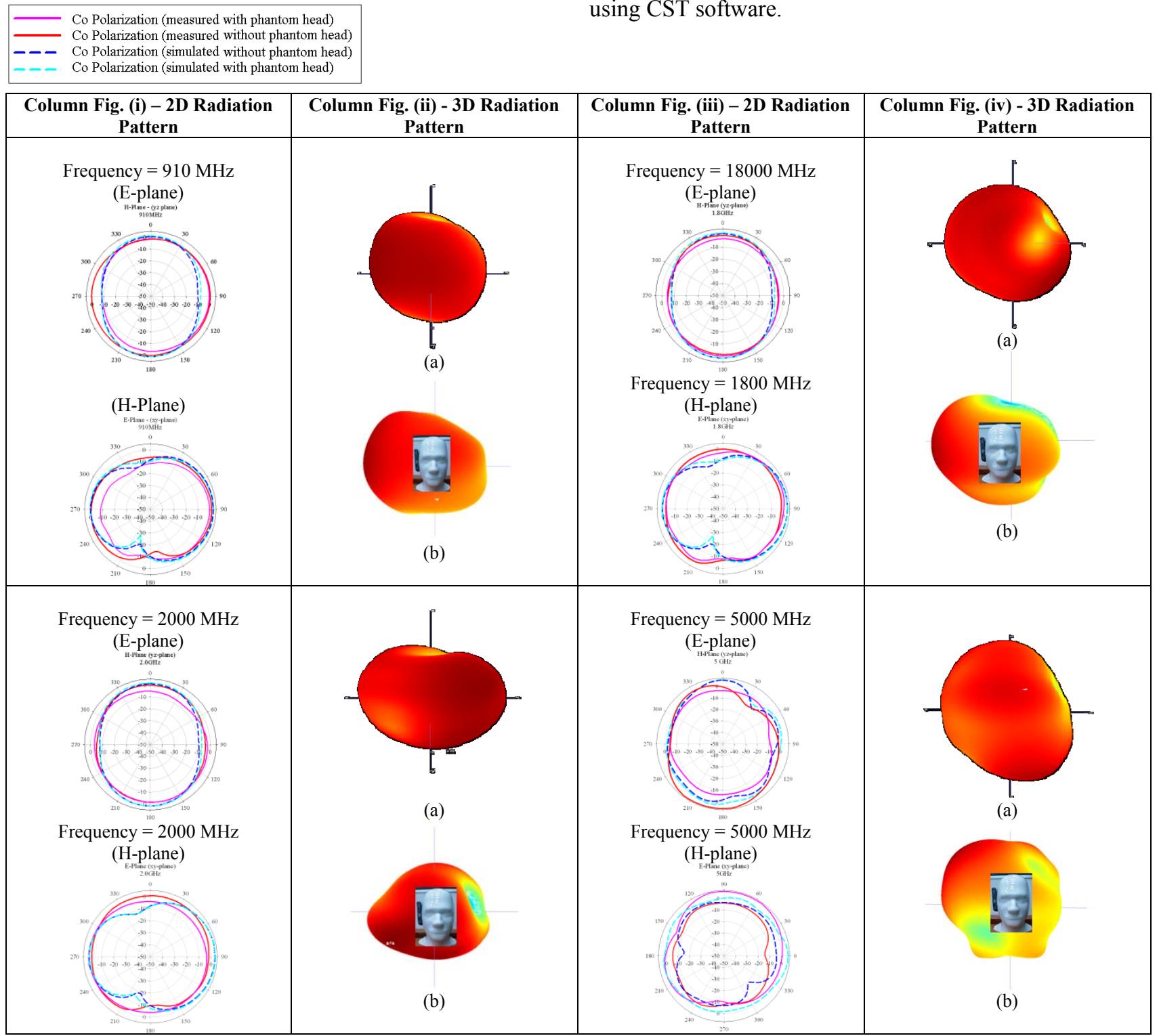

Fig. 7: 2D and 3D radiation pattern of F -PIFA. (a) 3D radiation pattern without phantom head, (b) 3D radiation pattern with phantom head 
TABLE V SAR RESULTS AT DIFFERENT OPERATING FREQUENCIES

\begin{tabular}{|c|c|}
\hline Freq (GHz) & SAR (W/kg) \\
\hline 0.9 & 0.255 \\
\hline 1.6 & 0.817 \\
\hline 2 & 0.996 \\
\hline 2.5 & 1.08 \\
\hline 4.8 & 1.47 \\
\hline 5 & 1.55 \\
\hline 5.8 & 1.59 \\
\hline 1.6 & 0.996 \\
\hline
\end{tabular}
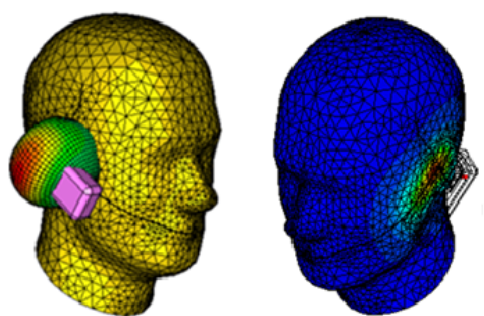

SAR ( $\mathrm{rmS}$ )

Type

Monitor

Frequency 2

Fig. 8: Simulated SAR with SAM Phantom Head using CST simulation tools

\section{CONCLUSION}

The presented PIFA antenna covers the required operating frequency range for mobile phone application which are GSM $900 \mathrm{MHz}, 1800 \mathrm{MHz}$, UMTS, WLAN and HiperLAN. An additional strip of copper is added to excite a low frequency resonance for GSM900. This antenna has also been applied in mobile phones and the $3 \mathrm{D}$ radiation patterns, gain and efficiency were measured using an anechoic chamber and were discussed. It is observed that the radiation pattern is omni-directional, thus, this antenna is extremely suitable for applications in mobile communication devices. Its sensitivity to both the vertical and horizontal polarization is of immense practical importance in mobile cellular communication applications because the antenna orientation is not fixed. This satisfies the requirements in wireless communication.

\section{REFERENCES}

[1] J. D. Kraus, R. J. Marhefka, Antennas for All Applications, McGrawHill, Boston, Third ed., 2002.

[2] R. B. Waterhouse, Microstrip Patch Antenna, Kluwer Academic Publishers, Boston, 2003.

[3] R. Garg, P. Bhartia, I. Bahl, A. Ittipiboon, Microstrip Antenna Design Handbook, Artech House, Boston, 2001.

[4] D.H. Werner, R.L. Haupt, P.L. Werner, "Fractal Antenna Engineering: The Theory and Design of Fractal Antenna Arrays", IEEE Antennas and Propagation Magazine, vol. 41, No.5, pp.37-59, October 1999.

[5] D. Delaune, N. Guan, K. Ito, "Simple Multiband Antenna for Mobile Phone Application Based on a Dual-arm Monopole Structure," PIERS Online, Vol. 4, No. 1, 2008.

[6] T. W. Hee, P. S. Hall, C. T. Song, "Fractal PIFA, Dipole and Monopole Antennas," IEEE Topical Conference on Wireless Communication Technology, pp.275-276, 2003.

[7] D. Choi, C. Shin, N. Kim, H. Shin, "Design and SAR Analysis of Broadband PIFA with Triple Band," PIERS Online, Vol. 1, No. 3, 290293, 2005.

[8] C. Puente, J. Romeu, A. Cardama, "Fractal-Shaped Antennas, in Frontiers in Electromagnetic," edited by D.H. Werner, R. Mittra, IEEE PRESS, 2000.

[9] J.P. Gianvittorio, S.Y. Rahmat, "Fractal Antennas: A Novel Antenna Miniaturization Technique, and Applications," IEEE, Antennas and Propagation Magazine, Vol.44, No.1, pp.20-36, February 2002.

[10] Y.X. Guo, I. Ang, M. Y. W. Chia, "Compact internal multiband antennas for mobile handsets," IEEE Antennas and Wireless Propagation Letters, Vol. 2, pp. 143 - 146, 2003

[11] K.-L. Wong, G.-Y. Lee, T.-W. Chiou, "A Low-Profile Planar Monopole Antenna for Multiband Operation of Mobile Handset," IEEE Transactions on Antennas and Propagation, Vol. 51, pp: 121-125, January 2003,

[12] M.A. Jensen, S.Y. Rahmat, "EM Interaction of Handset Antennas and Human in Personal communication", Proceeding of the IEEE, Vol. 83, pp. 7, 1995.

[13] S. Khalatbari, S. Dariush, A.A. Mirzaee, H.A. Sadafi, "Calculating SAR in two models of the human head exposed to mobile phones radiation at 900 and $1800 \mathrm{MHz}$, Progress in Electromagnetic Research Symposium, PIER Online, Vol. 2, pp. 104-109, 2006. 